\title{
Evaluation of the In Vivo Therapeutic Effects of Radix Paeoniae Rubra Ethanol Extract with the Hypoglycemic Activities Measured from Multiple Cell-Based Assays
}

\author{
Chia-Chuan Chang, ${ }^{1}$ Wei Yuan, ${ }^{2}$ Yun-Lian Lin, ${ }^{3}$ Ren-Shyan Liu, ${ }^{4}$ \\ Yi-Chen Juan, ${ }^{5}$ Wan-Hua Sun, ${ }^{6}$ Huey Jen Tsay, ${ }^{7}$ Hsiu-Chen Huang, \\ Yu-Ching Lee, ${ }^{9,10}$ and Hui-Kang Liu ${ }^{11,12}$ \\ ${ }^{1}$ School of Pharmacy, College of Medicine, National Taiwan University, Taipei, Taiwan \\ ${ }^{2}$ Department of Psychiatry, Cheng Hsin General Hospital, Taipei, Taiwan \\ ${ }^{3}$ Department of Chinese Pharmaceutical Sciences and Chinese Medicine Resources, China Medical University, Taichung, Taiwan \\ ${ }^{4}$ Department of Nuclear Medicine, Taipei Veterans General Hospital, Taipei, Taiwan \\ ${ }^{5}$ Institute of Pharmacology, National Yang-Ming University, Taipei, Taiwan \\ ${ }^{6}$ Department of Life Sciences and Institute of Genome Sciences, National Yang-Ming University, Taipei, Taiwan \\ ${ }^{7}$ Institute of Neuroscience, Brain Research Center, National Yang-Ming University, Taipei, Taiwan \\ ${ }^{8}$ Department of Applied Science, National Hsinchu University of Education, Hsinchu, Taiwan \\ ${ }^{9}$ The Centre of Translational Medicine, Taipei Medical University, Taipei, Taiwan \\ ${ }^{10}$ The Ph.D. Program for Medical Biotechnology, College of Medical Science and Technology, Taipei Medical University, Taipei, Taiwan \\ ${ }^{11}$ Division of Basic Chinese Medicine, National Research Institute of Chinese Medicine, Taipei, Taiwan \\ ${ }^{12}$ Ph.D. Program for the Clinical Drug Discovery from Herbal Medicine, College of Pharmacy, Taipei Medical University, Taipei, Taiwan
}

Correspondence should be addressed to Hui-Kang Liu; hk.liu@nricm.edu.tw

Received 11 July 2016; Revised 24 October 2016; Accepted 3 November 2016

Academic Editor: Darren R. Williams

Copyright (C) 2016 Chia-Chuan Chang et al. This is an open access article distributed under the Creative Commons Attribution License, which permits unrestricted use, distribution, and reproduction in any medium, provided the original work is properly cited.

Background. Radix Paeoniae Rubra (Chi Shao) contains several phytochemicals with hypoglycemic actions. Current research aims to explore potential insulinotropic effects and long-term therapeutic efficacy of such herb against type 2 diabetes. Methods. Composition analysis for the ethanol extract (PRExt) was executed by high performance liquid chromatography. Polyphenol-enriched fraction was characterized by high pressure size exclusion chromatography. Multiple cell platforms were employed to evaluate hypoglycemic bioactivities. In animal experiments, blood glucose, the homeostasis model assessment (HOMA)-index assessment, glucose tolerance test, and in vivo glucose uptake were all measured. Additional effects of PRExt on obesity and hepatic steatosis were evaluated by serum and histological analysis. Results. PRExt provides multiple hypoglycemic effects including the enhancement of glucose-mediated insulin secretion. Pentagalloylglucose and polyphenol-enriched fraction are two insulinotropic constituents. Moreover, PRExt intraperitoneal injection causes acute hypoglycemic effects on fasted $\mathrm{db} / \mathrm{db}$ mice. Oral administration of PRExt ( $200 \mathrm{mg} / \mathrm{kg}$ b.w.) gradually reduces blood glucose in $\mathrm{db} / \mathrm{db}$ mice to the level similar to that in C57J/B6 mice after 30 days. The improvement of glucose intolerance, HOMA-index, and in vivo glucose uptake is evident in addition to the weight loss effect and attenuation of hepatic steatosis. Conclusion. PRExt is an effective antidiabetic herbal extract with multiple hypoglycemic bioactivities.

\section{Introduction}

Diabetes mellitus (DM) is a major health issue, affecting more than 180 million people worldwide. Type 2 diabetes (T2D) affects more people than does type 1 diabetes and the typical comorbidities are central obesity and fatty liver [1]. Hyperglycemia in T2D patients is the consequence of both insulin resistance and beta-cell dysfunction or failure [2]. Therefore, 
an effective antidiabetic agent should both improve insulin sensitivity and enhance beta-cell function. Herbal medicine containing multiple hypoglycemic constituents has a great potential for fulfilling such requirement.

Radix Paeoniae Rubra (Chi Shao) is prescribed in Traditional Chinese Medicine (TCM) to enhance blood circulation and eliminate blood stasis and is usually employed for treating diabetics, for instance, Xue-Fu-Zhu-Yu decoction and Keishi-Bukuryo-Gan [3, 4]. Recently, we demonstrated that an ethanol extract of Radix Paeoniae Rubra could suppress transcription of the hepatic phosphoenolpyruvate carboxykinase (PEPCK) gene [5].

It was identified that the insulin sensitizing effect of chemical constituents from Radix Paeoniae Rubra is modulated by the inhibition of protein-tyrosine phosphatase 1B [6]. Pentagalloylglucose, another Radix Paeoniae Rubra constituent, acts like an insulin mimetic by binding to the insulin receptor [2,7]. Additionally, pentagalloylglucose and tannin acids inhibit adipogenesis and counteract obesity [8-10]. Several pharmacological effects of paeoniflorin have been demonstrated, including hypoglycemic, hypolipidemic, and antifatty liver activities $[5,7,11-14]$. Finally, paeonol inhibits intestinal glucose absorption and provides antioxidant effect $[15,16]$.

Despite the well-known hypoglycemic, antiadipogenesis, and antiobesity effects of constituents from Radix Paeoniae Rubra, the glucose-mediated insulinotropic effect of Radix Paeoniae Rubra extract and constituents on insulin secreting cells remained to be evaluated. On the other hand, the longterm therapeutic effects of Radix Paeoniae Rubra extract in the context of T2D remain unclear. Therefore, we intend to answer these questions by testing the efficacy of Radix Paeoniae Rubra extract and/or constituents in cell-based platforms as well as in a mouse model of T2D.

\section{Methods}

2.1. Preparation of the Ethanol Extract of Radix Paeoniae Rubra (Chi Shao). The ethanol extract of Radix Paeoniae Rubra (PRExt) was prepared as previously described [5] with some modifications. Briefly, $2 \mathrm{~kg}$ of the whole dried root from Paeonia lactiflora Pall. was extracted by $80 \%$ ethanol (EtOH) overnight. For chemical profiling of the extract, a high performance liquid chromatography (HPLC) apparatus (Shimadzu, Japan) comprising a LC-10AT pump, a SPD-10AV UV-visible spectrophotometric detector, and a Cosmosil 5C18-AR-II $(4.6 \mathrm{~mm} \times 250 \mathrm{~mm})$ column was used. The mobile phase was set as follows: solvent $\mathrm{A}, 0.1 \%$ formic acid in $\mathrm{H}_{2} \mathrm{O}$; solvent $\mathrm{B}, 0.1 \%$ formic acid in acetonitrile; $0-10 \mathrm{~min}, \mathrm{~B}=2-5 \%$; $10-$ 20 min, $\mathrm{B}=5-12 \%$; $20-32 \mathrm{~min}, \mathrm{~B}=12-30 \%$; $32-36 \mathrm{~min}, \mathrm{~B}$ $=20-30 \% ; 36-50 \mathrm{~min}, \mathrm{~B}=30-50 \% ; 50-60 \mathrm{~min}, \mathrm{~B}=50-$ $100 \%$. The flow rate was set to $1 \mathrm{~mL} / \mathrm{min}$. The preparation of polyphenol-enriched fraction (PEF) was previously described [7]. High Pressure Size Exclusion Chromatography (HPSEC) profiling of PEF was carried out on a size exclusion column (Bio-Gel G3000 $\mathrm{XL}$ ).

2.2. Cell Culture. The rat hepatoma cell line H4IIE cells were cultured in Dulbecco's Modified Eagle's Medium (DMEM) containing $1 \mathrm{~g} / \mathrm{L}$ glucose, $5 \%(\mathrm{v} / \mathrm{v})$ fetal bovine serum (FBS), and $1 \%(\mathrm{v} / \mathrm{v})$ antibiotics $(100 \mathrm{U} / \mathrm{mL}$ penicillin and $0.1 \mathrm{~g} / \mathrm{L}$ streptomycin) [7]. Rat insulin secreting cell line, BRIN-BD11 cells, were routinely cultured with RPMI-1640 containing $2 \mathrm{~g} / \mathrm{L}$ glucose, $10 \mathrm{mM}$ HEPES, and $1.0 \mathrm{mM}$ sodium pyruvate and supplemented with $10 \%$ (v/v) FBS and $1 \%$ (v/v) antibiotics [17]. In terms of L6 rat skeletal muscle cell, undifferentiated L6 myoblast was cultured in DMEM containing $1 \mathrm{~g} / \mathrm{L}$ glucose, $10 \%(\mathrm{v} / \mathrm{v}) \mathrm{FBS}$, and $1 \%$ antibiotic/antimycotic solution at a low density. Cells were discarded after being passaged over 8 generations. For myotube differentiation, L6 myoblast was seeded into 12 -well plates at a density of $1 \times 10^{5}$ cells/well in DMEM, 2\% (v/v) FBS, and 1\% antibiotic/antimycotic solution. Medium was replaced every three days and matured myotubes were formed 7 days after seeding [18]. For routing culture, cell lines were maintained at $37^{\circ} \mathrm{C}$ in an atmosphere of $5 \% \mathrm{CO}_{2}$ and $95 \%$ air.

2.3. Reverse-Transcription PCR. The measurement of PEPCK and beta-actin mRNA was previously described [19]. In short, total RNA extracted from treated H4IIE cells was reversetranscribed. Then, $50 \mathrm{ng}$ of cDNA was used in a PCR reaction to amplify the beta-actin or PEPCK genes. In terms of primer sequences, annealing temperature was used for PCR reaction, beta-actin: $5^{\prime}$-CGTAAAGACCTCTATGCCAA- $3^{\prime}$ and $5^{\prime}$ AGCCATGCCAAATGTGTCAT $-3^{\prime} / 57^{\circ} \mathrm{C} / 349 \mathrm{bp}$; PEPCK: $5^{\prime}$-AAGGCCGCACCATGTATGTC- $3^{\prime}$ and $5^{\prime}$-AGCAGTGAGTTCCCACCGTAT- $3^{\prime} / 57^{\circ} \mathrm{C} / 319 \mathrm{bp}$. Finally, PCR products were quantified using GeneTools 3.06 (Syngene, Frederick, USA).

2.4. Glucose Uptake Assay. A 2-(N-(7-Nitrobenz-2-oxa-1,3diazol-4-yl)Amino)-2-deoxyglucose (2-NBDG) uptake assay was carried out based on a previously published protocol [20]. Differentiated L6 myotubes were serum-starved 4 hours prior to exposure to each constituent for 30 minutes at $37^{\circ} \mathrm{C}$. Cells were then incubated with 2-NBDG $(100 \mu \mathrm{M})$ in KrebsRinger Bicarbonate Buffer (KRBB) for 1 hour at $37^{\circ} \mathrm{C}$. Finally, the fluorescence intensity of cell lysate was quantified using an M5 spectrophotometer (Molecular Devices, CA, USA) using an excitation/emission wavelength of 465/540 nm and normalized by protein concentration of each lysate.

2.5. Acute Insulin Secretion Test. The acute insulin secretion test has been previously described [21]. Briefly, seeded BRINBD11 cells were preincubated with $\mathrm{KRBB}$ (1.1 mM glucose) for 40 minutes at $37^{\circ} \mathrm{C}$. Cells were incubated with each constituent for 20 minutes at $37^{\circ} \mathrm{C}$. Test medium was then collected and insulin levels in the medium were measured using an Homogeneous Time Resolved Fluorescence (HTRF) insulin assay (Cisbio, USA).

2.6. Animal Husbandry and In Vivo Evaluation of Hypoglycemic Activity. The use of male C57J/B6 mice and db/db mice (obtained from the National Laboratory Animal Center, Tainan, Taiwan) was approved by the Animal Research Committee at the National Research Institute of Chinese Medicine. All procedures were in accordance with The Guide 
for the Care and Use of Laboratory Animals (NIH publication, 85-23, revised 1996) and the Guidelines of the Animal Welfare Act.

C57J/B6 mice received standard chow and $\mathrm{db} / \mathrm{db}$ mice were fed high-fat chow (high-fat diet) made from standard chow supplemented with extra lard $(20 \% \mathrm{w} / \mathrm{w})$, cholesterol $(1 \% \mathrm{w} / \mathrm{w})$, and cholic acid $(0.1 \% \mathrm{w} / \mathrm{w})$. For evaluation of acute hypoglycemic effect of PRExt, fasted $\mathrm{db} / \mathrm{db}$ mice with blood sugars $>500 \mathrm{mg} / \mathrm{dL}$ were randomly grouped and anesthetized by intraperitoneal injection with pentobarbital $(30 \mathrm{mg} / \mathrm{kg})$. Once initial blood sugar was measured from a cut tail tip using a commercial glucometer (Bioptik Technology, Taiwan), mice received either the vehicle (saline) or PRExt via intraperitoneal injection. Blood glucose was measured within the next 12 hours. In terms of long-term administration, experimental procedures began when the animals were 10 weeks old (the age at which fasting blood glucose in $\mathrm{db} / \mathrm{db}$ mice rose above $400 \mathrm{mg} / \mathrm{dL}$ ). During the course of the experiment, $\mathrm{db} / \mathrm{db}$ mice received vehicle $\left(\mathrm{dH}_{2} \mathrm{O}\right)$ or PRExt $(200 \mathrm{mg} / \mathrm{kg})$ daily. C57J/B6 mice received vehicle $\left(\mathrm{dH}_{2} \mathrm{O}\right)$ only. Treatment was administrated via oral gavage using a stomach tube. Blood sugar was measured from a cut tail tip every 3 days in total of 30 days.

2.7. Intravenous Glucose Tolerance Test (IVGTT). To perform an intravenous glucose tolerance test, mice were fasted overnight and then administered a glucose solution $(1 \mathrm{~g} / \mathrm{kg}$ body weight) via the tail vein. Animals were anesthetized by pentobarbital $(30 \mathrm{mg} / \mathrm{kg}$ of body weight, i.p.) for these procedures. Blood sugar was measured at $0,15,30,60$, and 120 minutes after the glucose was administered.

2.8. Small-Animal Positron Emission Tomography (PET) Scanning. The ability of the mice to absorb glucose was evaluated using micro-PET scanning [22]. Briefly, mice were first anesthetized with isoflurane ( $2 \%$ in $100 \%$ oxygen). A total of $100 \mu \mathrm{Ci}\left[{ }^{18} \mathrm{~F}\right] 2$-fluorodeoxyglucose (FDG) dissolved in saline was then injected into each animal through the tail vein. After 1 hour, each mouse was placed on a Concorde microPET R4 scanner (Concorde Microsystems, Knoxville, TN) for radioactivity scanning. The region of interest (ROI) in the skeletal muscle was selected, and a cylinder calibration method was used to convert the units of the micro-PET images from counts per second (cps) per voxel (cps/voxel) to $\mathrm{nCi}$ per $\mathrm{cc}(\mathrm{nCi} / \mathrm{cc})$. The results were further normalized to the blood sugar level of each animal and presented as uptake radioactivity $(\mathrm{nCi} / \mathrm{cc}) /$ serum glucose $(\mathrm{mg} / \mathrm{dL})$.

2.9. Serum Biochemical Analysis. Serum triglycerides were measured using a FUJI DRI-CHEM 3000 (Fuji Photo Film Co., Tokyo, Japan). Serum insulin concentrations were quantified using a Luminex multiplex assay (cat\#: MENDO-75K05, Millipore Corporation, Bedford, MA). The homeostasis model assessment for insulin resistance (HOMA-IR = fasting blood glucose $[\mathrm{mM}] \times$ fasting insulin $[\mu \mathrm{U} / \mathrm{mL}] / 22.5)$ and the homeostasis model assessment for beta-cell function (HOMA-B $=20 \times$ fasting insulin $[\mu \mathrm{U} / \mathrm{mL}] /$ fasting blood glucose $[\mathrm{mM}]-3.5)$ were then assessed [23].
2.10. Histopathological Examinations. A portion of liver was fixed with $4 \%(\mathrm{w} / \mathrm{v})$ paraformaldehyde and slides made from paraffin-embedded tissue were used for hematoxylin and eosin (H\&E) and Periodic Acid-Schiff (PAS) staining to visualize tissue morphology and determine the glycogen content, respectively. Additionally, the slides of frozen tissue sections were stained with Oil red O (ORO) to quantify neutral lipid and fatty acid contents [23].

2.11. Statistics. Significant differences between groups were determined using a Student's $t$-test (Mann-Whitney test) or a one-way analysis of variance (ANOVA) with a Tukey-Kramer test. Results were presented as the mean \pm SEM. Differences were considered significant if $p<0.05$.

\section{Results}

3.1. Chemical Analysis of Four Radix Paeoniae Rubra Constituents in Radix Paeoniae Rubra Extract (PRExt). Representative HPLC and HPSEC profiles of Radix Paeoniae Rubra extract (PRExt) and reference compounds are shown in Figure 1. HPLC peaks representing PRExt constituents, paeoniflorin (retention time $=34.657 \mathrm{~min}$ ), pentagalloylglucose (retention time $=40.436 \mathrm{~min}$ ), and paeonol (retention time $=53.338 \mathrm{~min}$ ) are identified in PRExt. The Lambda max $(\lambda \max )$ information for all the chromatograms was listed as below: PRExt: UV $\lambda \max (\mathrm{MeOH}, \log \varepsilon) 230$ (3.08), 273 (2.19) nm; paeoniflorin: UV $\lambda \max (\mathrm{MeOH}, \log \varepsilon) 230$ (2.43), $276(0.22) \mathrm{nm}$; pentagalloylglucose: UV $\lambda \max (\mathrm{MeOH}, \log \varepsilon)$ 228 (2.50), 267 (1.80), $294(1.91) \mathrm{nm}$; paeonol: UV $\lambda$ max $(\mathrm{MeOH}, \log \varepsilon) 232$ (2.50), 311 (2.08) nm; PEF: UV $\lambda \max$ $(\mathrm{MeOH}, \log \varepsilon) 234$ (2.53), 312 (2.12), 356 (1.93) nm. The yield of fractions and compounds: paeoniflorin: $56 \mathrm{mg} / \mathrm{g}$, pentagalloylglucose: $20.9 \mathrm{mg} / \mathrm{g}$, paeonol: $0.68 \mathrm{mg} / \mathrm{g}$, polyphenolenriched fraction (PEF): $<66 \mathrm{mg} / \mathrm{g}$.

Both peaks of PRExt representing paeoniflorin and pentagalloylglucose were further confirmed with mass spectrometry in positive and negative mode, respectively (see Supplementary Figures 1 and 2 of the Supplementary Material available online at http://dx.doi.org/10.1155/2016/3262790). Due to the chemical properties of polyphenol-enriched fraction as macromolecules, chemical profile analysis was performed by employing HPSEC. As shown in Figure 1(e), two major HPSEC peaks are observed and appeared at retention times of 10 and 12 minutes. Estimated molecular weights of these peaks are 73.479 and $13.693 \mathrm{kDa}$, respectively.

3.2. Pharmacological Evaluation of the Hypoglycemic Actions of PRExt and the Four Constituents. We compared the pharmacological activities of the herbal extract (PRExt) and the four constituents of PRExt (paeoniflorin, pentagalloylglucose, paeonol, and PEF) using three cells lines (liver, muscle, and pancreatic beta cells). In the liver cell line (H4IIE), dexamethasone $(500 \mathrm{nM})$ and 8-bromo-cAMP $(100 \mu \mathrm{M})$ induced PEPCK transcription, and insulin $(10 \mathrm{nM})$ played a dominant role in suppressing this upregulation $(p<0.001)$ (Figure 2(a)). Additionally, PRExt $(25 \mu \mathrm{g} / \mathrm{mL})$ suppressed PEPCK mRNA expression $(p<0.001)$. Next, we performed 


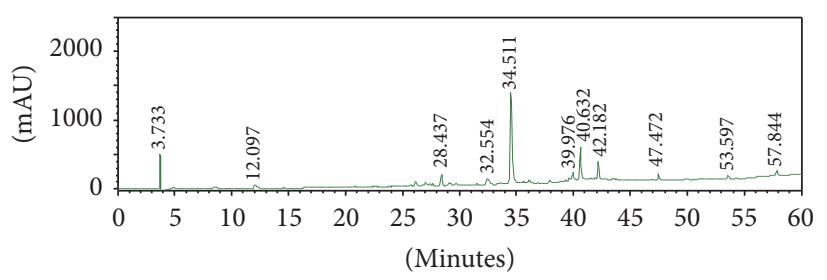

(a)

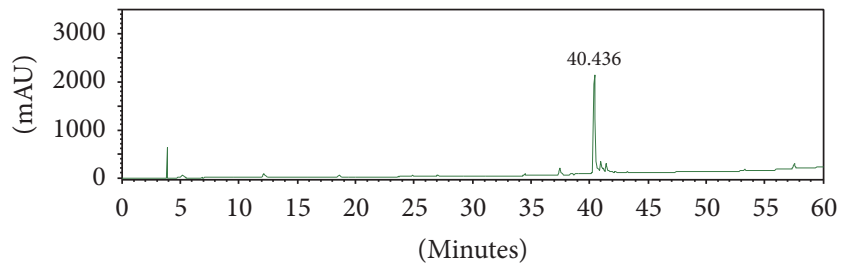

(c)

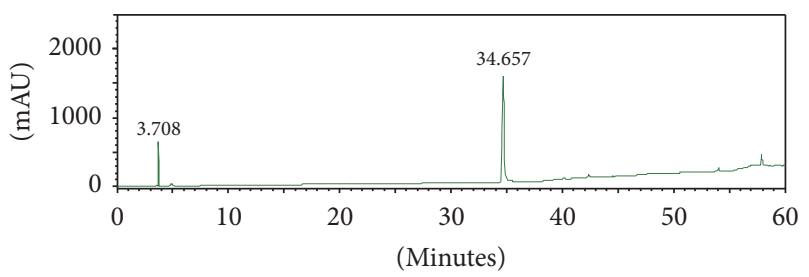

(b)

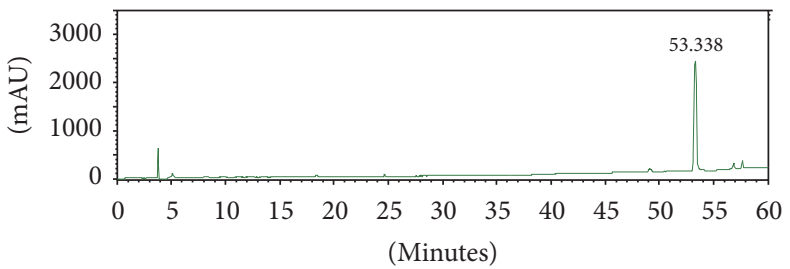

(d)

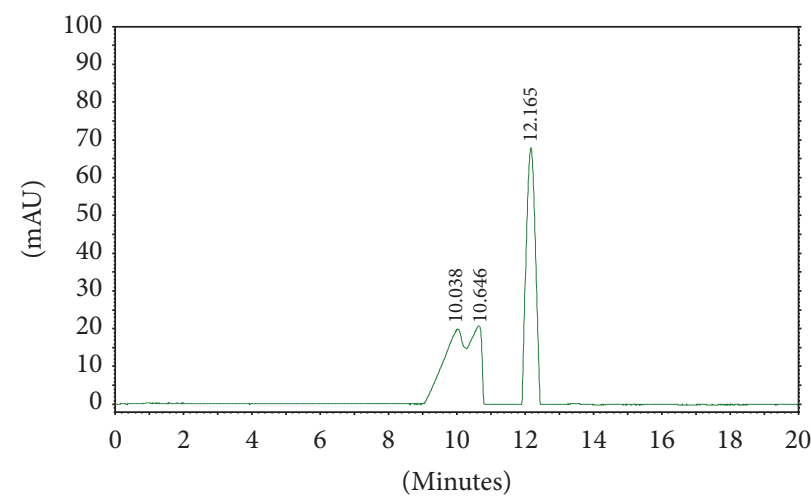

(e)

FIgURE 1: Chromatography profiles of PRExt and chemical constituents. Representative HPLC and HPSEC profiles of (a) PRExt, (b) paeoniflorin, (c) pentagalloylglucose, (d) paeonol, and (e) polyphenol-enriched fraction (PEF).

a glucose uptake assay in differentiated L6 myotubes. As shown in Figure 2(b), 2-NBDG uptake by L6 muscle cells significantly increased after exposure to insulin $(100 \mathrm{nM})$ for 30 minutes $(p<0.001)$. Treatment with PRExt $(50 \mu \mathrm{g} / \mathrm{mL})$ significantly stimulated glucose uptake after 30 minutes $(p<$ 0.01 ).

Finally, we evaluated the acute insulinotropic effects of PRExt and the four constituents on BRIN-BD11 pancreatic islet cells exposed to $16.7 \mathrm{mM}$ glucose. As shown in Figure 2(c), PRExt enhanced insulin secretion by these in a dosedependent manner. Significant insulinotropic effects induced by PRExt and exendin-4 were observed at a concentration of $6.25 \mu \mathrm{g} / \mathrm{mL}(p<0.05)$ and $100 \mathrm{nM}$, respectively. In terms of the four constituents, only pentagalloylglucose and PEF enhanced insulin secretion (Figures 3(b) and 3(d)). The increase was significant at a concentration of pentagalloylglucose and PEF at $2.5 \mu \mathrm{g} / \mathrm{mL}(p<0.01)$ and $10 \mu \mathrm{g} / \mathrm{mL}(p<$ $0.001)$, respectively.

\subsection{PRExt Administration Improves Glycemic Control in $\mathrm{db} / \mathrm{db}$} Mice. We found a dose-dependent inhibition of fasting blood sugar in $\mathrm{db} / \mathrm{db}$ mice treated with PRExt at doses of $200 \mathrm{mg} / \mathrm{kg}$ and higher (Figure 4(a)). As a result, we administered PRExt at $200 \mathrm{mg} / \mathrm{kg}$ to $\mathrm{db} / \mathrm{db}$ mice to evaluate its long-term therapeutic efficacy. As shown in Figure 4(b), untreated db/db mice experienced sustained hyperglycemia over 30 days, with a state blood sugar significantly higher than that of untreated C57J/B6 mice $(p<0.001)$. When $\mathrm{db} / \mathrm{db}$ mice were treated with PRExt $(200 \mathrm{mg} / \mathrm{kg})$ for 30 days, the elevated blood sugar gradually decreased and after 30 days was significantly reduced when compared with untreated mice $(p<0.001)$.

As shown in Figure 5(a), there was a nearly threefold increase in HOMA-IR in $\mathrm{db} / \mathrm{db}$ mice compared with C57J mice $(p<0.05)$, and PRExt treatment significantly reduced this HOMA-IR in $\mathrm{db} / \mathrm{db}$ mice $(p<0.01)$. As illustrated in Figure 5(b), a twofold reduction in HOMA-B\% was observed in $\mathrm{db} / \mathrm{db}$ mice compared to C57J mice $(p<0.05)$, but HOMA-B\% in $\mathrm{db} / \mathrm{db}$ mice was more comparable to that of C57J mice after treatment with PRExt $(p<0.001)$. In Figure 5(c), untreated $\mathrm{db} / \mathrm{db}$ mice were obviously glucose intolerant; in contrast, glucose intolerance clearly improved in mice treated with PRExt. Finally, as illustrated in Figure 5(d), a one-hour ${ }^{18}$ FDG PET scan of the brain, limbs, heart, and bladder revealed poor glucose absorption and biodistribution in the $\mathrm{db} / \mathrm{db}$ mice compared to C57J/B6 mice. However, upon PRExt treatment, glucose biodistribution clearly improved. 


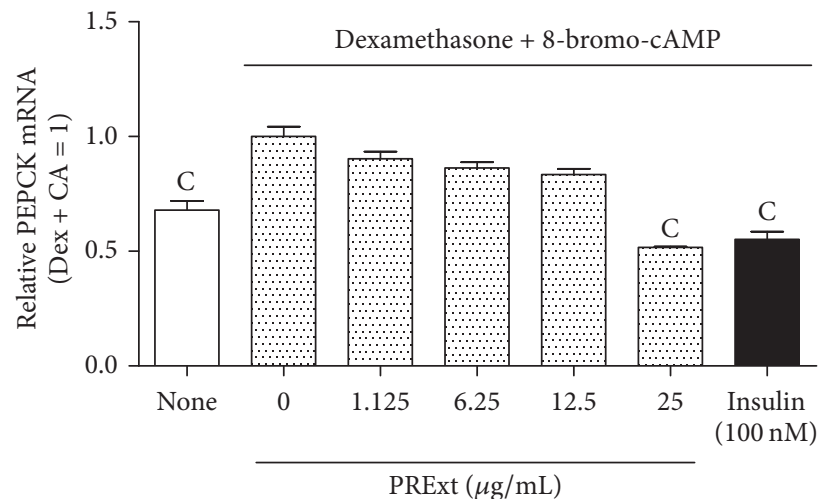

(a)

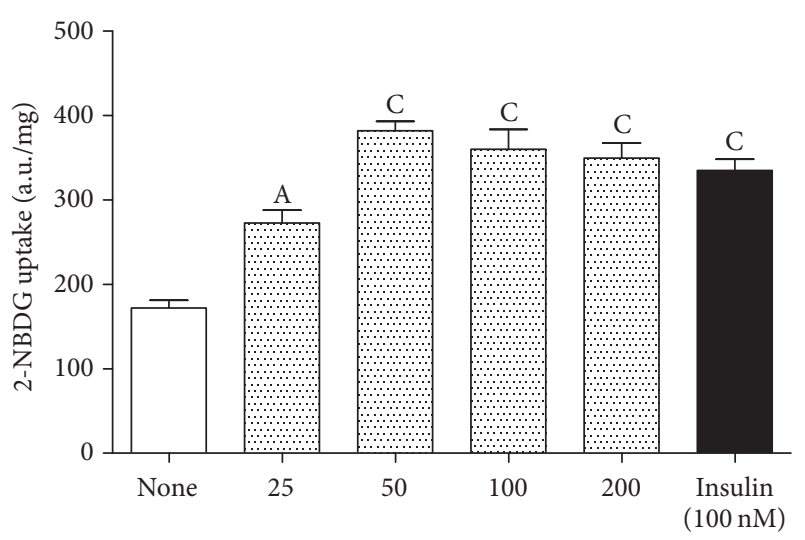

PRExt $(\mu \mathrm{g} / \mathrm{mL})$

(b)

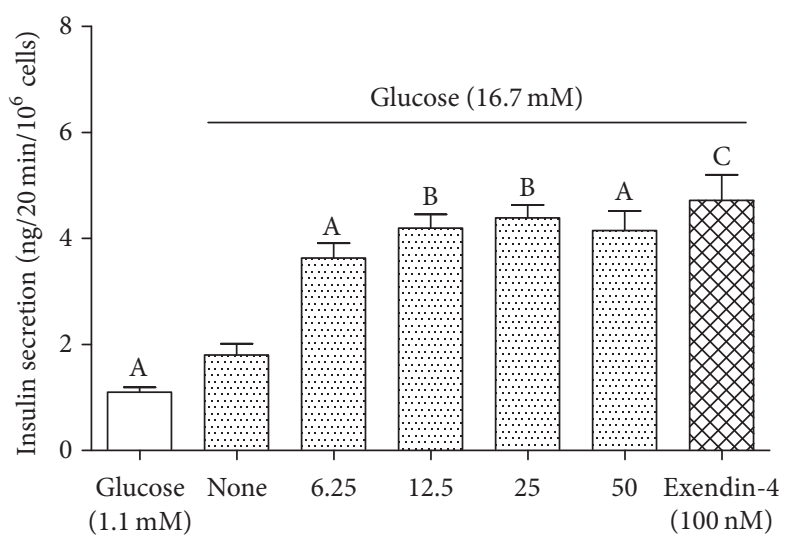

PRExt $(\mu \mathrm{g} / \mathrm{mL})$

(c)

FIgURE 2: Multiple hypoglycemic activities of PRExt. (a) A dose-dependent suppressive effect of PRExt on PEPCK mRNA expression. Insulin $(100 \mathrm{nM})$ served as a reference drug. Data are presented as the mean \pm SEM $\left(n=3\right.$ /group). ${ }^{C} p<0.001$ when compared with mRNA levels in H4IIE cells treated with dexamethasone and 8-bromo-cAMP. (b) The glucose uptake activity of L6 myotubes exposed to PRExt or insulin $(100 \mathrm{nM})$ for 30 minutes prior to performing a 2-NBDG $(100 \mu \mathrm{M})$ uptake assay. Data are presented as the mean \pm SEM $(n=6 /$ group). ${ }^{\mathrm{A}} p<0.05$ and ${ }^{\mathrm{C}} p<0.001$ when compared with untreated L6 myotubes. (c) The insulinotropic effect of PRExt on BRIN-BD11 cells under hyperglycemic condition (16.7 mM glucose). Exendin- $4(100 \mathrm{nM})$ was used as a reference drug. Data are presented as the mean \pm SEM $(n=$ 4/group). ${ }^{\mathrm{A}} p<0.05,{ }^{\mathrm{B}} p<0.01$, and ${ }^{\mathrm{C}} p<0.001$ when compared with insulin levels under hyperglycemic conditions (16.7 mM glucose).

As seen in Figure 5(e), glucose absorption was higher in the upper limbs than in the lower limbs of C57J/B6 mice $(p<$ 0.001), but there was no difference in glucose absorption between the limbs of $\mathrm{db} / \mathrm{db}$ mice, whether they had been treated with PRExt or not. However, there was a twofold increase in glucose within individual limbs of $\mathrm{db} / \mathrm{db}$ mice upon PRExt treatment $(p<0.001)$.

\subsection{PRExt Administration Ameliorates Both Obesity and Hep-} atic Steatosis in $\mathrm{db} / \mathrm{db}$ Mice. Obesity and hepatic steatosis are two common comorbidities observed in $\mathrm{db} / \mathrm{db}$ mice. In our study, the body mass of untreated $\mathrm{db} / \mathrm{db}$ mice was twofold that of C57J/B6 mice ( $p<0.001$; Figure 6(a)), while PRExt administration resulted in an approximately $15 \%$ decrease in body mass in $\mathrm{db} / \mathrm{db}$ mice $(p<0.001)$. Despite this decrease, the body mass of PRExt treated $\mathrm{db} / \mathrm{db}$ mice remained significantly higher than that of C57J/B6 mice $(p<0.01)$. Additionally, serum triacylglyceride levels were increased nearly fivefold in untreated $\mathrm{db} / \mathrm{db}$ mice compared with C57J/B6 mice $(p<0.001$; see Figure 6(b)); however, a significant decrease in serum triacylglyceride was observed after PRExt treatment $(p<0.001)$. Serum triacylglyceride levels nevertheless remained significantly higher in PRExt treated $\mathrm{db} / \mathrm{db}$ than in C57J/B6 mice $(p<0.05)$.

As shown in Figure 6(c), abnormal lipid accumulation in the liver, as judged by $\mathrm{H} \& \mathrm{E}$ staining of liver tissue, was evident in untreated $\mathrm{db} / \mathrm{db}$ mice, and these results correlated with heavy Oil red $\mathrm{O}$ staining from the same tissue sections. Additionally, the loss of PAS staining in the liver tissue of $\mathrm{db} / \mathrm{db}$ mice further indicated the loss of hepatic glycogen. However, 


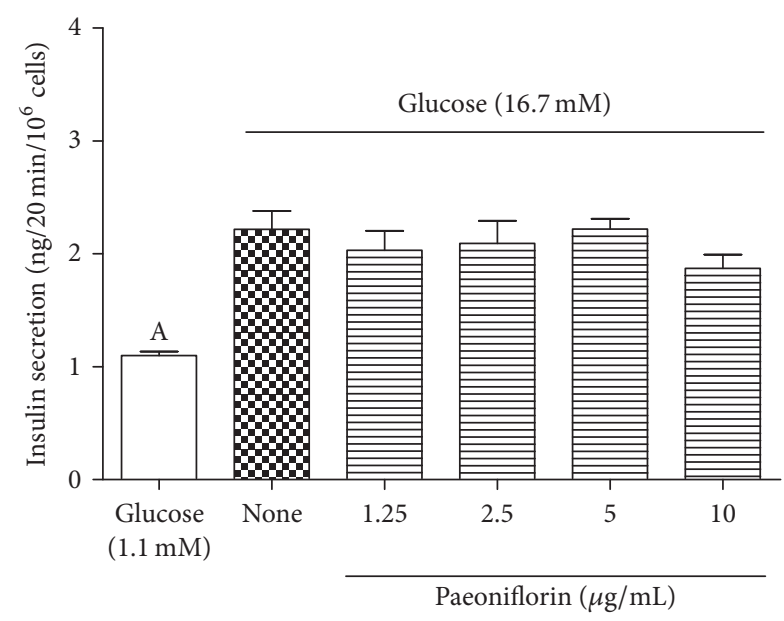

(a)

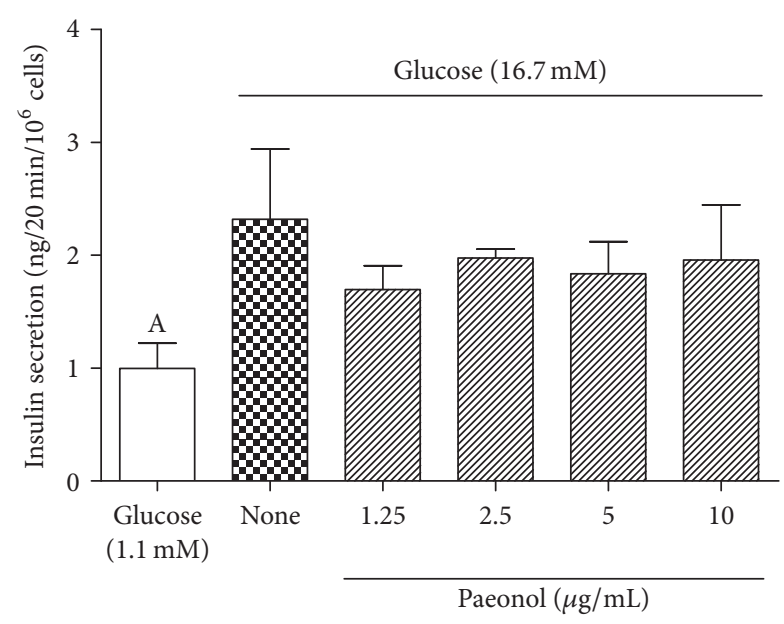

(c)

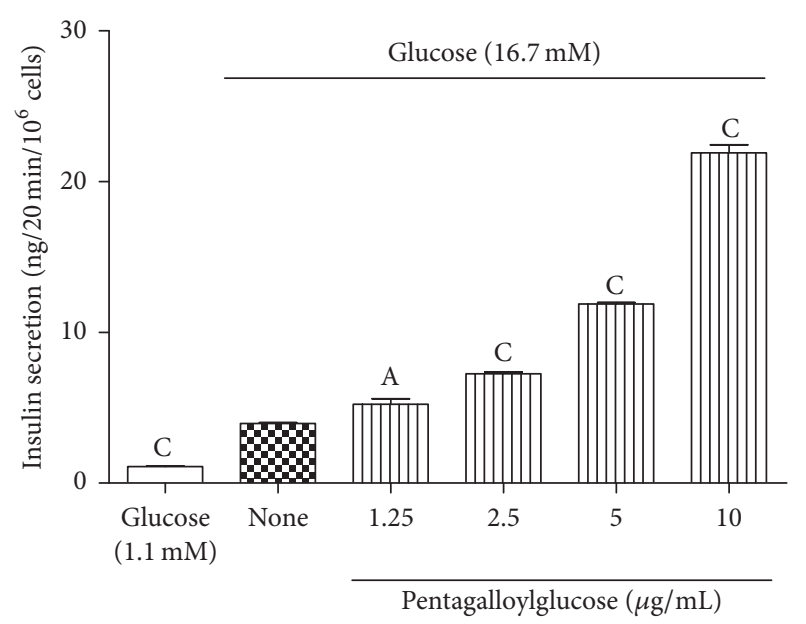

(b)

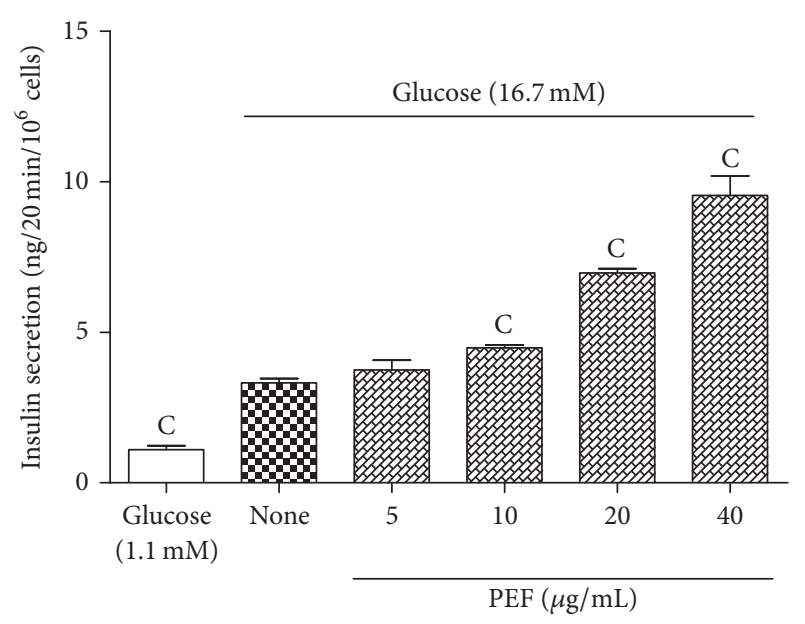

(d)

FIGURE 3: Insulinotropic effects of four constituents of Radix Paeoniae Rubra on glucose-stimulated insulin secretion of BRIN-BD11 cells. The insulinotropic effects of (a) paeoniflorin, (b) pentagalloylglucose, (c) paeonol, and (d) PEF on BRIN-BD11 cells under hyperglycemic conditions (16.7 mM glucose). Data are presented as the mean \pm SEM $(n=4-8 /$ group $) .{ }^{\mathrm{A}} p<0.05$ and ${ }^{\mathrm{C}} p<0.001$ when compared with insulin levels under hyperglycemic conditions ( $16.7 \mathrm{mM}$ glucose).

when $\mathrm{db} / \mathrm{db}$ mice were treated with PRExt, the histological characteristics of nonalcoholic fatty liver disease (NAFLD) in $\mathrm{db} / \mathrm{db}$ mice appeared to be attenuated, as seen by histological patterns similar to those of liver tissue obtained from C57J/B6 mice.

Liver injury is judged by serum level of glutamic-pyruvate transaminase (GPT). In the current study, serum GPT in untreated $\mathrm{db} / \mathrm{db}$ mice was significantly elevated compared with that of C57J/B6 mice ( $p<0.01$; see Figure 6(d)). Corresponding with the observed attenuation of fatty liver pathology in $\mathrm{db} / \mathrm{db}$ mice treated with PRExt, serum GPT also significantly decreased in these mice $(p<0.05)$.

\section{Discussion}

In the current study, we hypothesized that PRExt, an herbal extract comprising many phytochemicals with beneficial antidiabetes effects, could meet the criteria for a hypoglycemic drug/health food. Therefore, through the use of liver, muscle, and pancreatic beta-cell lines, we evaluated the hypoglycemic actions of PRExt and each of the four constituents. Hepatic gluconeogenesis is regulated by hormone-mediated transcription of the rate limiting enzymes including PEPCK [24]. Using H4IIE liver cells, we firstly demonstrated that the suppressive activity of PRExt on dexamethasone and 8bromo-cAMP induced PEPCK mRNA expression as previously described [5]. Pentagalloylglucose and the tanninpolymers containing fraction were identified as the two constituents responsible for this effect [7].

Additionally, peripheral glucose uptake by muscle tissue accounts for two-thirds of postprandial glucose disposal [25]. In the current study, PRExt increasingly stimulated glucose uptake in differentiated L6 myotubes up to a concentration of $50 \mu \mathrm{g} / \mathrm{mL}$. Paeoniflorin, pentagalloylglucose, and tannins 


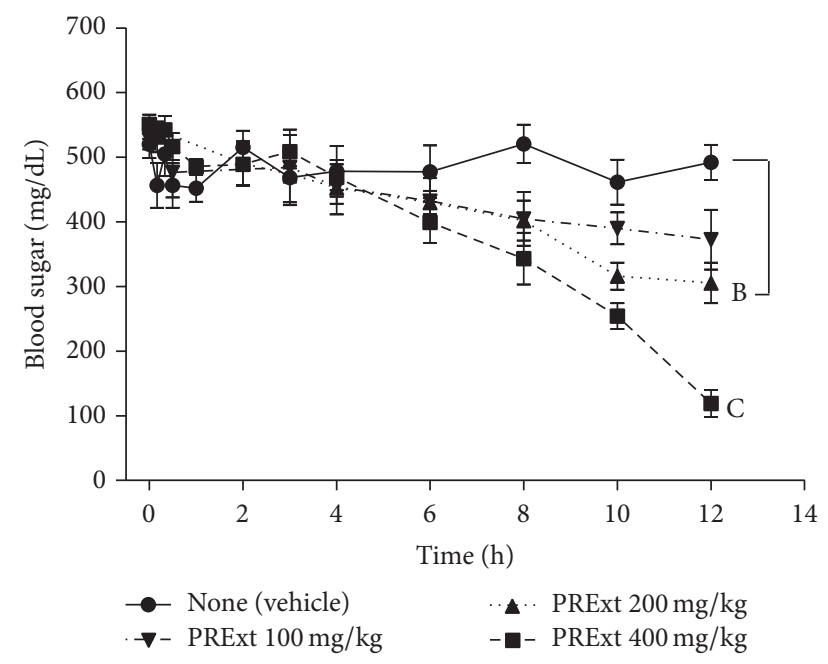

(a)

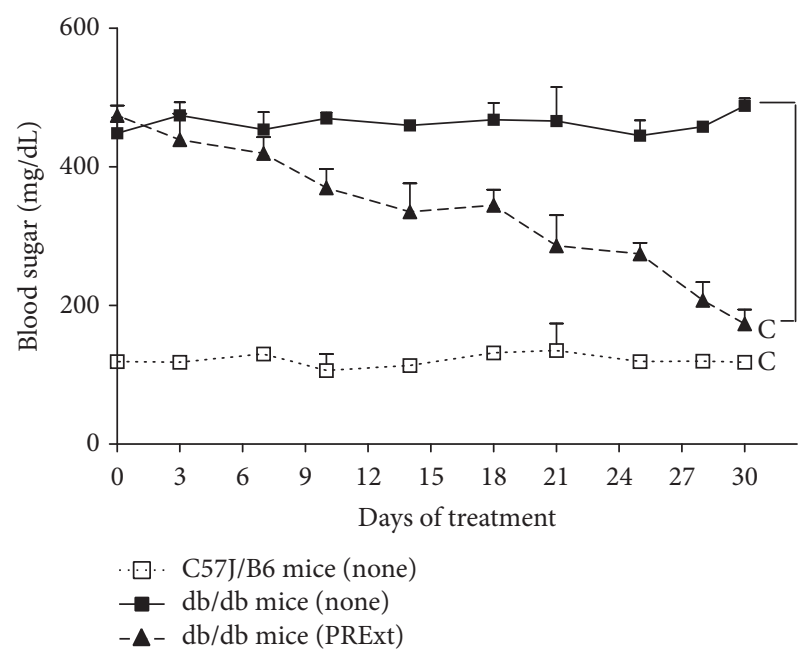

(b)

FIGURE 4: Evaluation acute and long-term hypoglycemic effects of PRExt on $\mathrm{db} / \mathrm{db}$ T2D mice. (a) Fasting blood glucose of $\mathrm{db} / \mathrm{db}$ mice were intraperitoneal injected with PRExt at indicated dosages. Acute blood glucose changes are recorded at $0,15 \mathrm{~min}, 30 \mathrm{~min}, 1 \mathrm{~h}, 2 \mathrm{~h}, 4 \mathrm{~h}$, $6 \mathrm{~h}, 8 \mathrm{~h}, 10 \mathrm{~h}$, and $12 \mathrm{~h}$, respectively. Data are presented as the mean \pm SEM ( $n=5$ /group). ${ }^{\mathrm{B}} p<0.01$ and ${ }^{\mathrm{C}} p<0.001$ when compared with data of vehicle group at $12 \mathrm{~h}$. (b) The long-term state blood sugar of C57J mice and $\mathrm{db} / \mathrm{db}$ control mice in the presence or absence of oral administration of PRExt $(200 \mathrm{mg} / \mathrm{kg} / \mathrm{day})$. Data are presented as the mean \pm SEM ( $n=6-10$ /group). ${ }^{C} p<0.001$ when compared with untreated $\mathrm{db} / \mathrm{db}$ mice.

have been reported to stimulate peripheral glucose uptake via various mechanisms [9, 10, 26-29]. We also have similar observations (data not shown). Because the 2-NDBG and ${ }^{18}$ FDG are both nonmetabolizable tracers, the increment of ${ }^{18}$ FDG content in limbs of $\mathrm{db} / \mathrm{db}$ mice treated with PRExt also suggested that glucose absorption in the skeletal muscle is enhanced by PRExt treatment.

How to maintain and promote glucose-mediated insulin secretion is one of the major issues for diabetes therapy. Finally, we describe for the first time the insulinotropic effect of PRExt using BRIN-BD11 pancreatic beta cells. Among the four PRExt constituents described here, only pentagalloylglucose and PEF enhanced glucose-stimulated insulin secretion. Considering functional insulin receptors are known to present in pancreatic beta cells and provide important role in regulating glucose-mediated insulin secretion; insulinotropic effect of pentagalloylglucose might result from its insulin mimetic property [29-31]. On the other hand, the underlying mechanism to explain insulinotropic effect of PEF remained to be investigated.

Acute hypoglycemic effect of Radix Paeoniae Rubra ethanol extract on diabetic rodents was shown previously [5]. Our results also clearly demonstrated that PRExt treatment effectively decreases fasting hyperglycemia in a dose-dependent manner. In terms of the long-term therapeutic efficacy, PRExt administration gradually attenuates diabetic hyperglycemia over 30 days and significantly improves the HOMA-index of $\mathrm{db} / \mathrm{db}$ mice. As a result, the improvement of glucose intolerance may be the combinational result of improved insulin resistance, beta-cell function, and peripheral glucose absorption in PRExt treated $\mathrm{db} / \mathrm{db}$ mice.

Obesity, hyperlipidemia, and NAFLD are related pathological factors causing insulin resistance and metabolic syndrome [32] as well as an increased risk for type 2 diabetes [33]. In our investigation, a loss of body associated with PRExt treatment was evident in $\mathrm{db} / \mathrm{db}$ mice. This decrease in body mass was associated with a reduction in fat pads (data not shown), reduction of serum triglyceride levels, and the attenuation of NAFLD-induced hepatic injury. In terms of hepatic pathohistological results, the vacuole morphology of the hepatic cytoplasm in $\mathrm{db} / \mathrm{db}$ mice after $\mathrm{H} \& \mathrm{E}$ staining was evident as a result of washing out the intracellular triacylglyceride. It is correlated with heavy Oil red $\mathrm{O}$ staining from the same tissue and companioned the loss of PAS staining which indicates the loss of hepatic glycogen. Those NAFLD features observed in $\mathrm{db} / \mathrm{db}$ mice were changed by PRExt administration. However, it should be noted that PRExt treatment was only partially effective, as only differences in body mass and serum triglyceride levels between treated and untreated mice are significant.

The present study indicates that the antidiabetic activity of PRExt is associated with the polyphenols present in PRExt. Polyphenols are well reported to have poor pharmacokinetic properties [34-36]; therefore, they lack drug-ability due to the requirement of high oral dosages. However, our results also pointed out the potential complementary actions of the constituents in PRExt because of the overlapping biological activity from different compounds. In addition, targeting multiple biological activities is also a good strategy for treating multifactorial disease such as diabetes; therefore, it may provide some explanation for the effectiveness of herbal extract with a pool of polyphenols in treating diabetic mice.

In conclusion, the present investigation provides novel evidence of insulinotropic effects of PRExt, pentagalloylglucose, and PEF on insulin secreting cells, BRIN-BD11 cells. Additionally, beneficial antidiabetic effects of the long-term PRExt $(200 \mathrm{mg} / \mathrm{kg}$ ) administration on $\mathrm{db} / \mathrm{db}$ mice were demonstrated. Our research results and literatures also suggest that paeoniflorin, pentagalloylglucose, and PEF can serve 


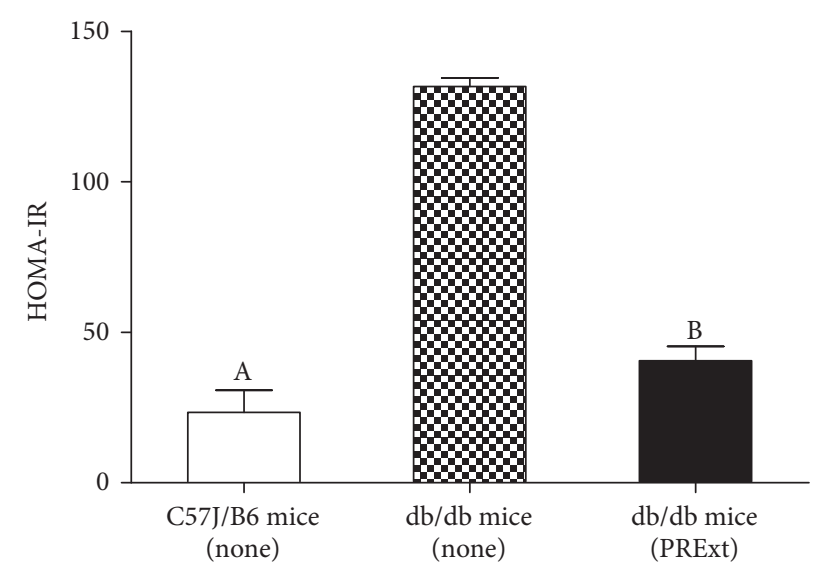

(a)

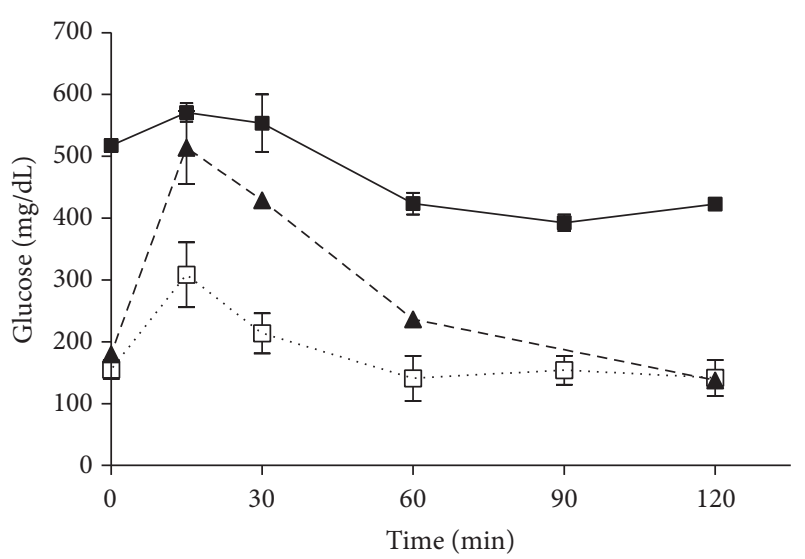

$\because \quad$ C57J/B6 mice (none)

- $\mathbf{\Delta -} \mathrm{db} / \mathrm{db}$ mice (PRExt)

(c)

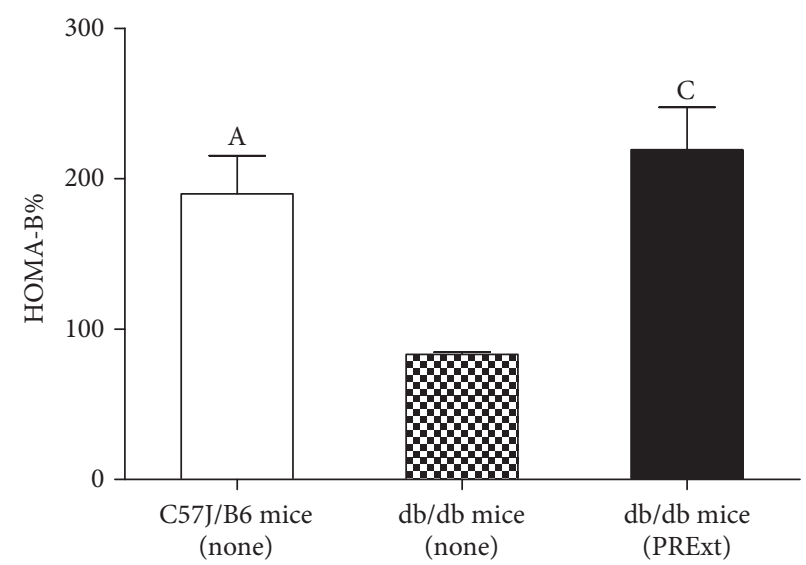

(b)

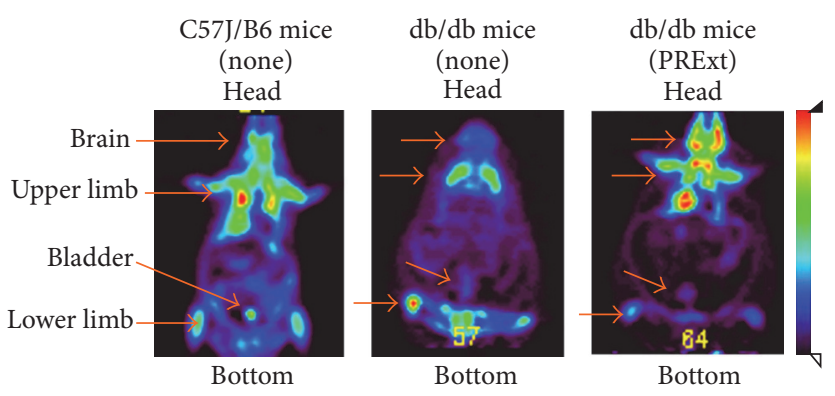

(d)

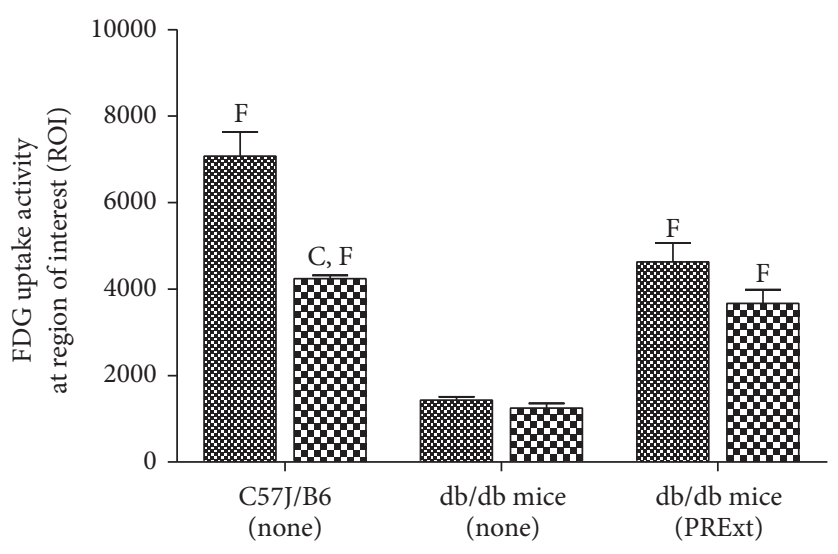

Waper limbs Lower limbs

(e)

FIgURE 5: Therapeutic effects of PRExt in treating dysglycemia in $\mathrm{db} / \mathrm{db}$ T2D mice. The results of (a) HOMA-IR, (b) HOMA-B\%, and (c) glucose tolerance of C57J mice and $\mathrm{db} / \mathrm{db}$ control mice in the presence or absence of PRExt treatment. Data are presented as the mean \pm SEM ( $n=6-10 /$ group). ${ }^{\mathrm{A}} p<0.01,{ }^{\mathrm{B}} p<0.05$, and ${ }^{\mathrm{C}} p<0.001$ when compared with untreated db/db mice. (d) Representative results of $2-\left[{ }^{18} \mathrm{~F}\right]$-fluorodeoxyglucose (FDG) biodistribution measured by micro-PET scanning. (e) Quantitative results of upper and lower limbs after FDG uptake. Data are presented as the mean \pm SEM ( $n=4$ /group). ${ }^{C} p<0.001$ when compared with FDG uptake activity between upper and lower limbs in the same mice. ${ }^{\mathrm{F}} p<0.001$ when compared with FDG uptake activity of the corresponding limb region in untreated db/db mice. 


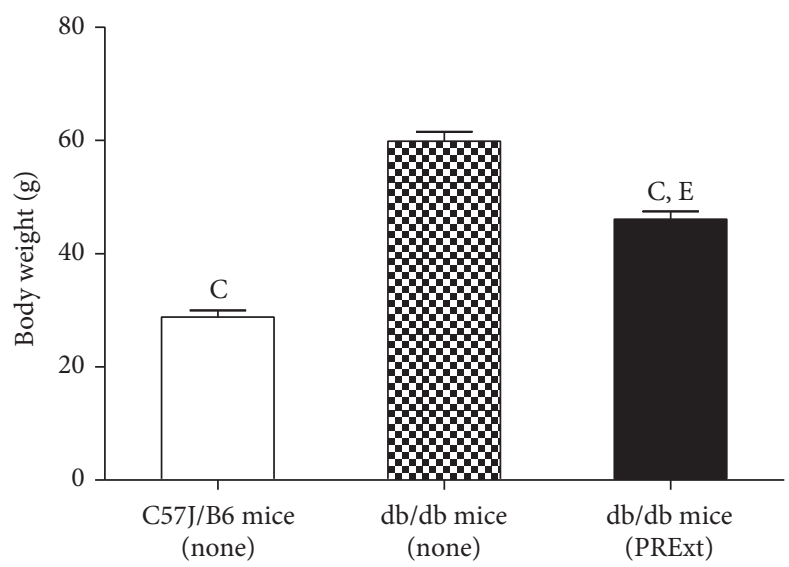

(a)

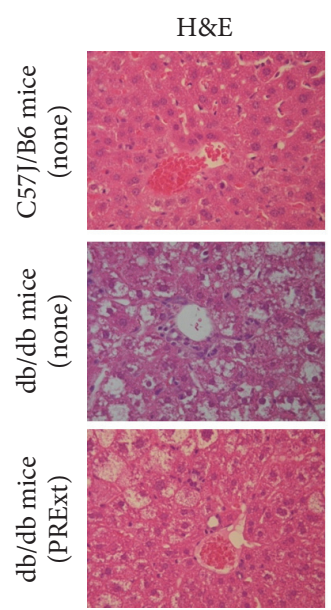

Oil Red O

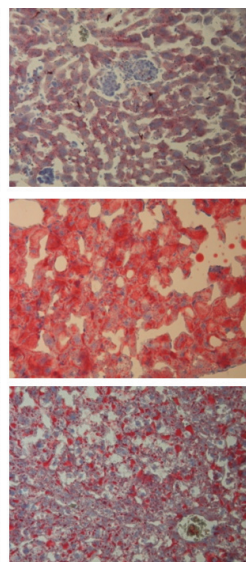

(c)

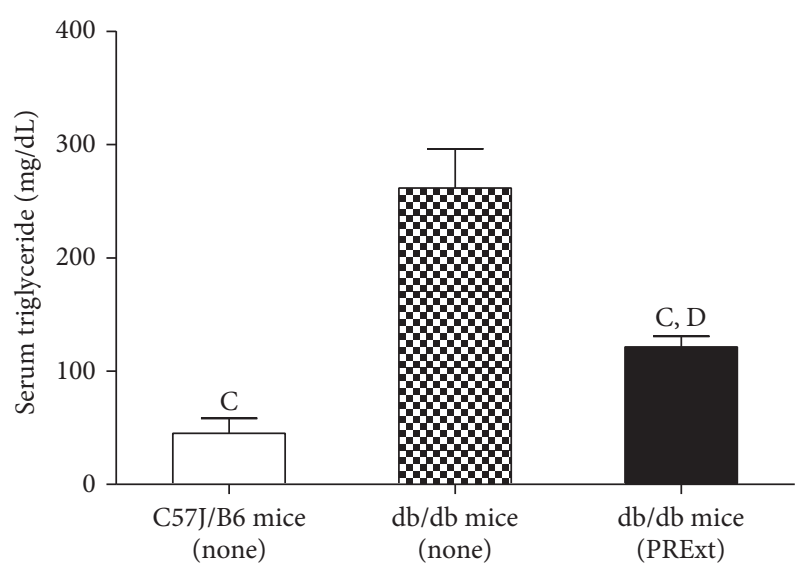

(b)

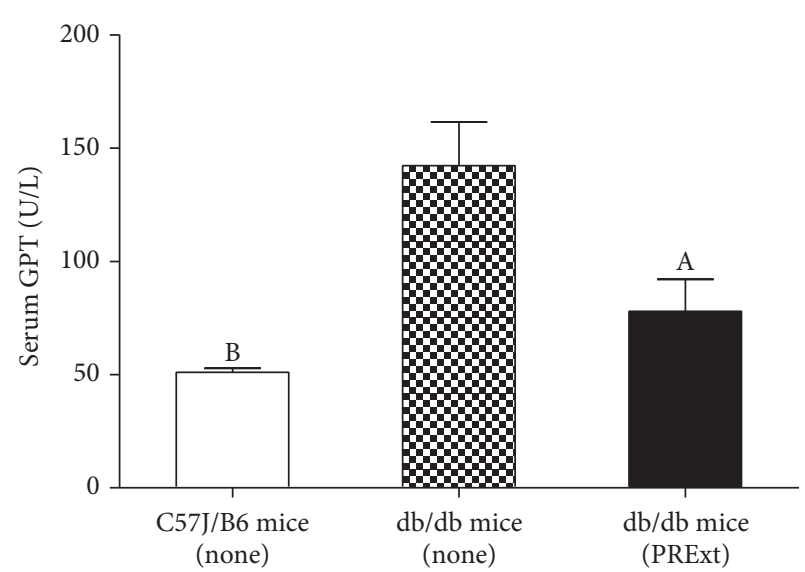

(d)

FIGURE 6: Effects of PRExt administration on the attenuation of obesity and hepatic steatosis in db/db mice. (a) Body weight and (b) serum triglyceride levels in $\mathrm{db} / \mathrm{db}$ control mice and mice treated with PRExt. (c) Representative results from mouse liver tissue sections stained with $\mathrm{H} \& \mathrm{E}$, Oil red O (ORO), and PAS stain. (d) Quantification of serum GPT levels in $\mathrm{db} / \mathrm{db}$ control mice and mice treated with PRExt. Data are presented as the mean \pm SEM $(n=6-10 /$ group $) .{ }^{\mathrm{A}} p<0.05,{ }^{\mathrm{B}} p<0.01$, and ${ }^{\mathrm{C}} p<0.001$ when compared to untreated db/db mice. ${ }^{\mathrm{D}} p<0.05$ and ${ }^{\mathrm{E}} p<0.01$ when compared to C57J/B6 mice.

as useful standards with hypoglycemic activities for a qualitycontrolled herbal extract made from Radix Paeoniae Rubra for the purpose of treating type 2 diabetes.

\section{Abbreviations}

FDG: $\quad\left[{ }^{18} \mathrm{~F}\right]$ 2-fluorodeoxyglucose

2-NBDG: 2-(N-(7-Nitrobenz-2-oxa-1,3-diazol-4yl)Amino)-2-deoxyglucose

cps: $\quad$ Counts per second

DM: $\quad$ Diabetes mellitus

DMEM: Dulbecco's Modified Eagle's Medium

EtOH: Ethanol

FBS: $\quad$ Fetal bovine serum

H\&E: Hematoxylin and eosin

IVGTT: Intravenous glucose tolerance test

KRBB: Krebs-Ringer Bicarbonate Buffer

NAFLD: Nonalcoholic fatty liver disease

ORO: Oil red $\mathrm{O}$
PEF: $\quad$ Polyphenol-enriched fraction

PAS: $\quad$ Periodic Acid-Schiff

PEPCK: Phosphoenolpyruvate carboxykinase

HOMA: Homeostasis model assessment

HTRF: Homogeneous Time Resolved Fluorescence

HPLC: High Performance Liquid Chromatography

HPSEC: High Pressure Size Exclusion Chromatography

ANOVA: One-way analysis of variance

PET: $\quad$ Positron Emission Tomography

ROI: $\quad$ Region of interest

PRExt: The ethanol extract of Radix Paeoniae Rubra

$\lambda$ max: The Lambda max

TCM: Traditional Chinese Medicine

T2D: $\quad$ Type 2 diabetes.

\section{Competing Interests}

The authors declare no conflict of interests. 


\section{Authors' Contributions}

Chia-Chuan Chang and Wei Yuan contributed equally to this paper.

\section{Acknowledgments}

The authors would like to thank the Taiwan Mouse Clinic at Academia Sinica, Taiwan, for their histopathology service. This work was funded by Ministry of Science and Technology, China (Grants MOST102-2320-B-077-003 for Hui-Kang Liu and MOST 103-2320-B-002-006-MY3 for Chia-Chuan Chang).

\section{References}

[1] J. E. Gerich, "Redefining the clinical management of type 2 diabetes: matching therapy to pathophysiology," European Journal of Clinical Investigation, vol. 32, supplement 3, pp. 46-53, 2002.

[2] B. Ahrén and G. Pacini, "Islet adaptation to insulin resistance: mechanisms and implications for intervention," Diabetes, Obesity and Metabolism, vol. 7, no. 1, pp. 2-8, 2005.

[3] C.-Y. Huang, Y.-T. Tsai, J.-N. Lai, and F.-L. Hsu, "Prescription pattern of Chinese herbal products for diabetes mellitus in Taiwan: A Population-Based Study," Evidence-Based Complementary and Alternative Medicine, vol. 2013, Article ID 201329, 10 pages, 2013.

[4] T. Nakagawa, H. Goto, H. Hikiami, T. Yokozawa, N. Shibahara, and Y. Shimada, "Protective effects of keishibukuryogan on the kidney of spontaneously diabetic WBN/Kob rats," Journal of Ethnopharmacology, vol. 110, no. 2, pp. 311-317, 2007.

[5] Y.-C. Juan, W.-J. Tsai, Y.-L. Lin et al., "The novel anti-hyperglycemic effect of Paeoniae radix via the transcriptional suppression of phosphoenopyruvate carboxykinase (PEPCK)," Phytomedicine, vol. 17, no. 8-9, pp. 626-634, 2010.

[6] J. Bu, J. N. Wang, and S. P. Gu, "Study on the chemical constituents of the PTP 1B inhibitory effective parts of Paeoniae Rubra Radix," Zhong Yao Cai, vol. 36, no. 11, pp. 1783-1785, 2013.

[7] Y.-C. Juan, C.-C. Chang, W.-J. Tsai, Y.-L. Lin, Y.-S. Hsu, and H.K. Liu, "Pharmacological evaluation of insulin mimetic novel suppressors of PEPCK gene transcription from Paeoniae Rubra Radix," Journal of Ethnopharmacology, vol. 137, no. 1, pp. 592600, 2011.

[8] Y. Ren, K. Himmeldirk, and X. Chen, "Synthesis and structureactivity relationship study of antidiabetic penta-O-galloyl-Dglucopyranose and its analogues," Journal of Medicinal Chemistry, vol. 49, no. 9, pp. 2829-2837, 2006.

[9] X. Liu, J.-K. Kim, Y. Li, J. Li, F. Liu, and X. Chen, “Tannic acid stimulates glucose transport and inhibits adipocyte differentiation in 3T3-L1 cells," Journal of Nutrition, vol. 135, no. 2, pp. 165-171, 2005.

[10] V. S. Muthusamy, S. Anand, K. N. Sangeetha, S. Sujatha, B. Arun, and B. S. Lakshmi, "Tannins present in Cichorium intybus enhance glucose uptake and inhibit adipogenesis in 3T3L1 adipocytes through PTP1B inhibition," Chemico-Biological Interactions, vol. 174, no. 1, pp. 69-78, 2008.

[11] F.-L. Hsu, C.-W. Lai, and J.-T. Cheng, "Antihyperglycemic effects of paeoniflorin and 8-debenzoylpaeoniflorin, glucosides from the root of Paeonia lactiflora," Planta Medica, vol. 63, no. 4, pp. 323-325, 1997.
[12] C. W. Lai, F. L. Hsu, and J. T. Cheng, "Stimulatory effect of paeoniflorin on adenosine A-1 receptors to increase the translocation of protein kinase $\mathrm{C}$ (PKC) and glucose transporter (GLUT 4) in isolated rat white adipocytes," Life Sciences, vol. 62, no. 17-18, pp. 1591-1595, 1998.

[13] H. O. Yang, W. K. Ko, J. Y. Kim, and H. S. Ro, "Paeoniflorin: an antihyperlipidemic agent from Paeonia lactiflora," Fitoterapia, vol. 75, no. 1, pp. 45-49, 2004.

[14] L. Zhang, B. Yang, and B. Yu, "Paeoniflorin protects against nonalcoholic fatty liver disease induced by a high-fat diet in mice," Biological and Pharmaceutical Bulletin, vol. 38, no. 7, pp. 10051011, 2015.

[15] C. H. Lau, C. M. Chan, Y. W. Chan et al., "Pharmacological investigations of the anti-diabetic effect of Cortex Moutan and its active component paeonol," Phytomedicine, vol. 14, no. 11, pp. 778-784, 2007.

[16] J. Liu, S. Wang, L. Feng et al., "Hypoglycemic and antioxidant activities of paeonol and its beneficial effect on diabetic encephalopathy in streptozotocin-induced diabetic rats," Journal of Medicinal Food, vol. 16, no. 7, pp. 577-586, 2013.

[17] Y.-S. Hsu, Y.-H. Kuo, H.-L. Cheng, P. R. Flatt, and H.-K. Liu, "Schizandra arisanensis extract attenuates cytokinemediated cytotoxicity in insulin-secreting cells," World Journal of Gastroenterology, vol. 18, no. 46, pp. 6809-6818, 2012.

[18] A. J. Ruiz-Alcaraz, H.-K. Liu, D. J. Cuthbertson et al., "A novel regulation of IRS1 (insulin receptor substrate-1) expression following short term insulin administration," Biochemical Journal, vol. 392, no. 2, pp. 345-352, 2005.

[19] C.-C. Chen, C.-Y. Hsu, C.-Y. Chen, and H.-K. Liu, "Fructus Corni suppresses hepatic gluconeogenesis related gene transcription, enhances glucose responsiveness of pancreatic betacells, and prevents toxin induced beta-cell death," Journal of Ethnopharmacology, vol. 117, no. 3, pp. 483-490, 2008.

[20] H. Kaji, T. Ishibashi, K. Nagamine, M. Kanzaki, and M. Nishizawa, "Electrically induced contraction of $\mathrm{C} 2 \mathrm{C} 12$ myotubes cultured on a porous membrane-based substrate with muscle tissue-like stiffness," Biomaterials, vol. 31, no. 27, pp. 6981-6986, 2010.

[21] H.-K. Liu, B. D. Green, P. R. Flatt, N. H. McClenaghan, and J. T. McCluskey, "Effects of long-term exposure to nicotinamide and sodium butyrate on growth, viability, and the function of clonal insulin secreting cells," Endocrine Research, vol. 30, no. 1, pp. 61-68, 2004.

[22] C.-H. Chang, H.-E. Wang, S.-Y. Wu et al., "Comparative evaluation of FET and FDG for differentiating lung carcinoma from inflammation in mice," Anticancer Research, vol. 26, no. 2, pp. 917-925, 2006.

[23] H.-K. Liu, Y.-C. Juan, Y.-H. Kuo et al., "Administration of a decoction of sucrose- and polysaccharide-rich radix astragali (Huang Qi) ameliorated insulin resistance and fatty liver but affected beta-cell function in type 2 diabetic rats," EvidenceBased Complementary and Alternative Medicine, vol. 2011, Article ID 349807, 11 pages, 2011.

[24] P. A. Lochhead, I. P. Salt, K. S. Walker, D. G. Hardie, and C. Sutherland, "5-Aminoimidazole-4-carboxamide riboside mimics the effects of insulin on the expression of the 2 key gluconeogenic genes PEPCK and glucose-6-phosphatase," Diabetes, vol. 49, no. 6, pp. 896-903, 2000.

[25] H. J. Woerle, C. Meyer, J. M. Dostou et al., "Pathways for glucose disposal after meal ingestion in humans," American Journal of Physiology-Endocrinology and Metabolism, vol. 284, no. 4, pp. E716-E725, 2003. 
[26] L.-M. Tang, I.-M. Liu, and J.-T. Cheng, "Stimulatory effect of paeoniflorin on adenosine release to increase the glucose uptake into white adipocytes of Wistar rat," Planta Medica, vol. 69, no. 4, pp. 332-336, 2003.

[27] J.-T. Cheng, T.-C. Chi, and I.-M. Liu, "Activation of adenosine A1 receptors by drugs to lower plasma glucose in streptozotocin-induced diabetic rats," Autonomic Neuroscience, vol. 83, no. 3, pp. 127-133, 2000.

[28] F. S. L. Thong, J. S. V. Lally, D. J. Dyck, F. Greer, A. Bonen, and T. E. Graham, "Activation of the Al adenosine receptor increases insulin-stimulated glucose transport in isolated rat soleus muscle," Applied Physiology, Nutrition and Metabolism, vol. 32, no. 4, pp. 701-710, 2007.

[29] Y. Li, J. Kim, J. Li et al., "Natural anti-diabetic compound 1,2, 3,4,6-penta-O-galloyl-D-glucopyranose binds to insulin receptor and activates insulin-mediated glucose transport signaling pathway," Biochemical and Biophysical Research Communications, vol. 336, no. 2, pp. 430-437, 2005.

[30] C. A. Aspinwall, J. R. T. Lakey, and R. T. Kennedy, "Insulinstimulated insulin secretion in single pancreatic beta cells," Journal of Biological Chemistry, vol. 274, no. 10, pp. 6360-6365, 1999.

[31] O. Le Bacquer, G. Queniat, V. Gmyr, J. Kerr-Conte, B. Lefebvre, and F. Pattou, "mTORC1 and mTORC2 regulate insulin secretion through Akt in INS-1 cells," Journal of Endocrinology, vol. 216, no. 1, pp. 21-29, 2013.

[32] G. M. Reaven, "Role of insulin resistance in human disease (syndrome X): an expanded definition," Annual Review of Medicine, vol. 44, pp. 121-131, 1993.

[33] M. Stumvoll, B. J. Goldstein, and T. W. van Haeften, "Type 2 diabetes: principles of pathogenesis and therapy," The Lancet, vol. 365, no. 9467, pp. 1333-1346, 2005.

[34] L.-C. Chen, M.-H. Lee, M.-H. Chou, M.-F. Lin, and L.-L. Yang, "Pharmacokinetic study of paeoniflorin in mice after oral administration of Paeoniae radix extract," Journal of Chromatography B: Biomedical Sciences and Applications, vol. 735, no. 1, pp. 33-40, 1999.

[35] C. Feng, M. Liu, X. Shi et al., "Pharmacokinetic properties of paeoniflorin, albiflorin and oxypaeoniflorin after oral gavage of extracts of Radix Paeoniae Rubra and Radix Paeoniae Alba in rats," Journal of Ethnopharmacology, vol. 130, no. 2, pp. 407-413, 2010.

[36] T. Matsumoto, Y. Matsubara, Y. Mizuhara et al., "Plasma pharmacokinetics of polyphenols in a traditional Japanese medicine, jumihaidokuto, which suppresses propionibacterium acnesinduced dermatitis in rats," Molecules, vol. 20, no. 10, pp. 1803118046, 2015. 


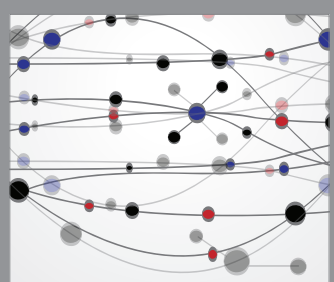

The Scientific World Journal
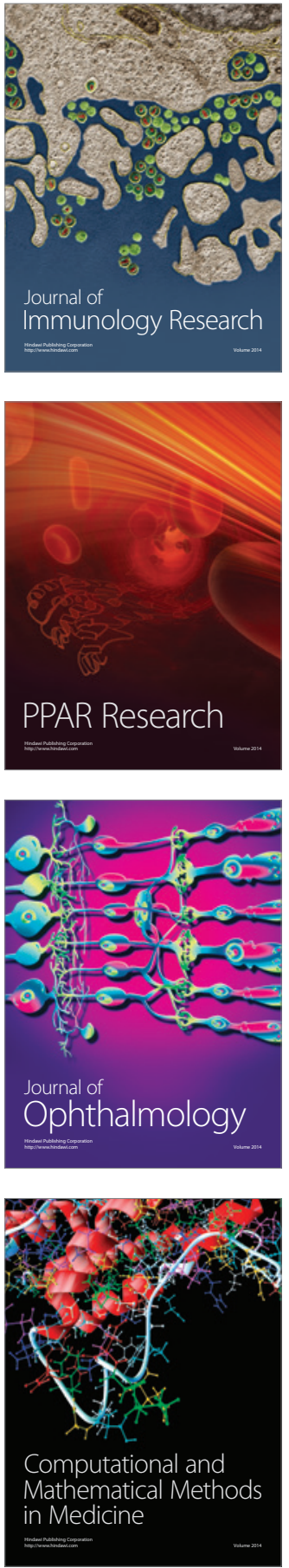

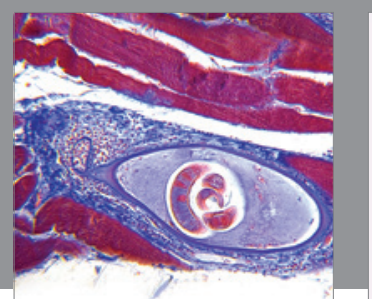

Gastroenterology Research and Practice

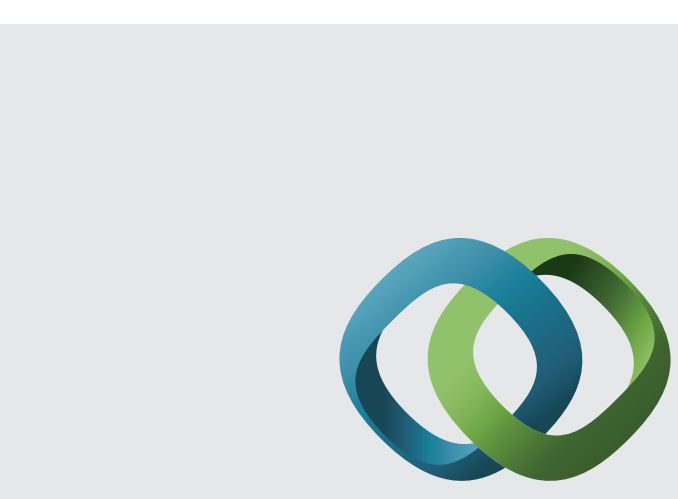

\section{Hindawi}

Submit your manuscripts at

http://www.hindawi.com
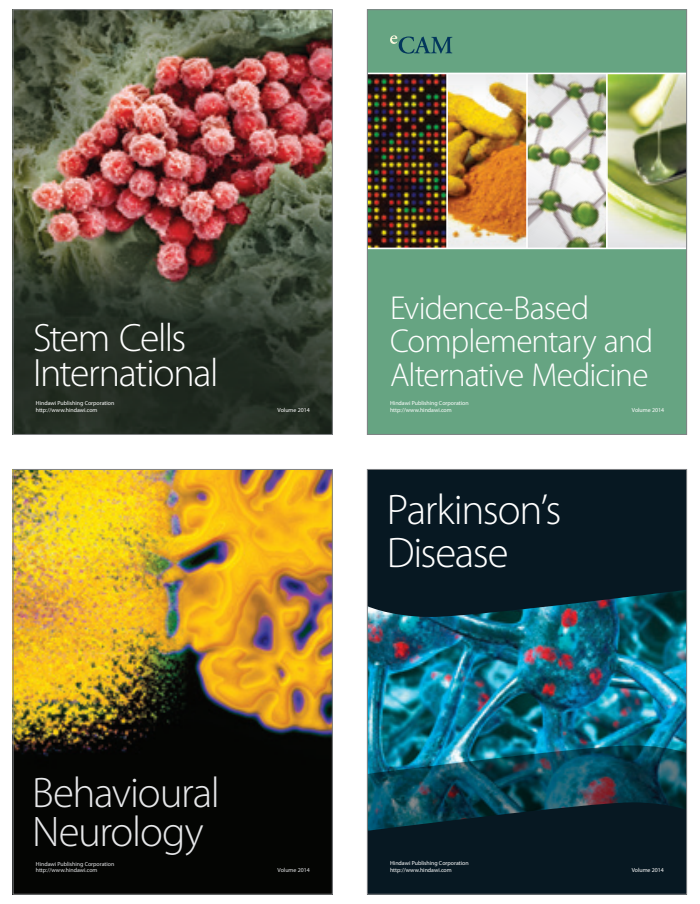
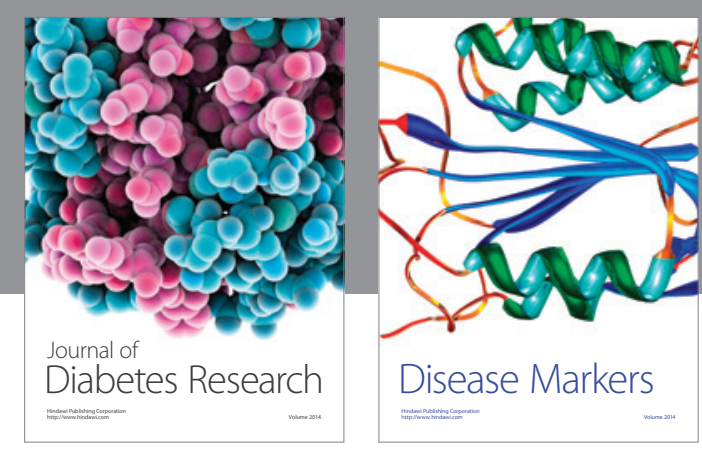

Disease Markers
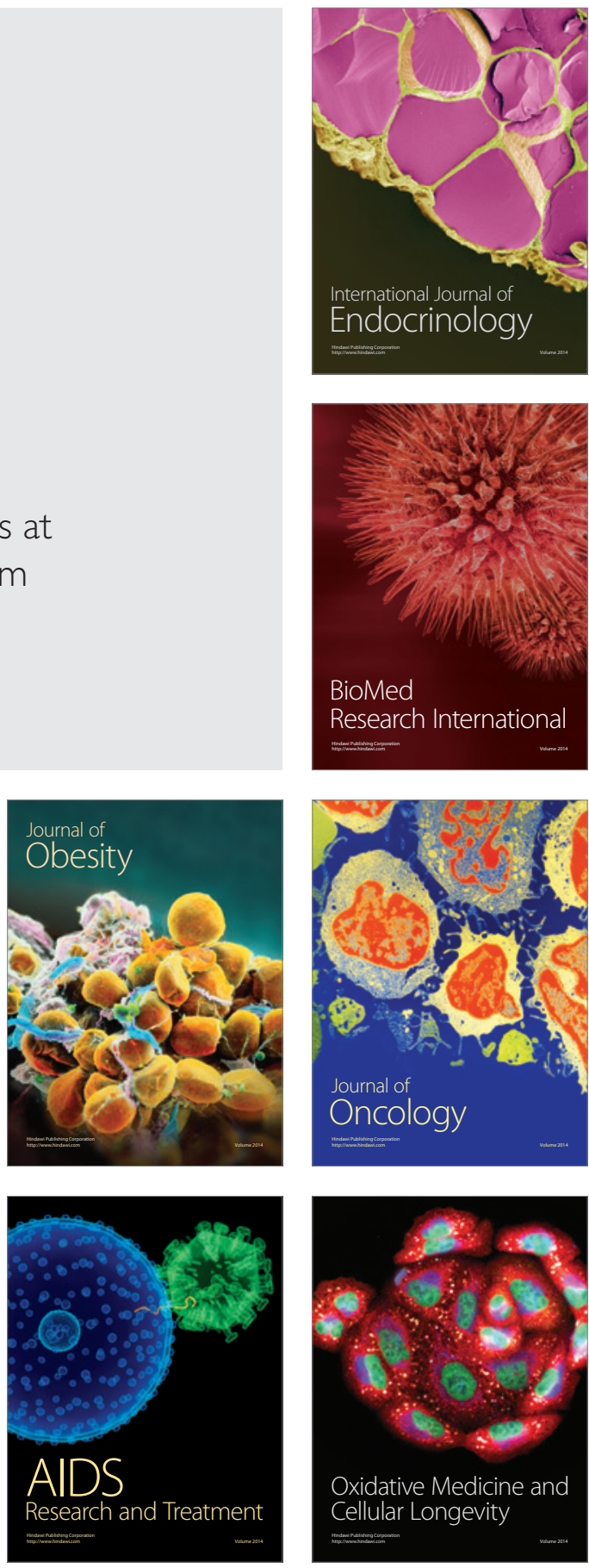